\title{
PENGARUH BUDAYA ORGANISASI, KOMPENSASI DAN GAYA KEPEMIMPINAN TERHADAP KINERJA KARYAWAN DI PERUSAHAN ROKOK (PR). SUMBER BAROKAH
}

\author{
*Anodia Tegar Pranatha, Nurul Qomari, Nurul Iman \\ Prodi Manajemen Fakultas Ekonomi dan Bisnis Universitas Bhayangkara, Indonesia
}

DOI: $10.46821 /$ benchmark.v1i1.18

\begin{abstract}
Abstrak
Tembakau adalah salah satu komoditas paling penting di Indonesia.Produk utama dari tembakau yang banyak diperdagangkan adalah rokok. Tujuan yang hendak dicapai dalam penelitian ini adalah untuk menguji dan menganalisa tentang adanya pengaruh budaya organisasi, kompensasi dan gaya kepemimpinan terhadap kinerja karyawan pada Pr. Sumber Barokah di Sidoarjo. Penelitian ini dilakukan pengambilan data dilakukan dengan bertemu dengan pemilik Pr. Sumber Barokah, setelah itu menyamakan konsep penelitian yang akan diteliti di lokasi tersebut. Dan akhirnya untuk mendapatkan data angket peneliti menyebarkan pernyataan-pernyataan yang telah disediakan didalam kuesioner, kuisoner tersebut dibagikan pada 89 responden secara acak. Teknik pengambilan data ini menggunakan random sampling dari data tersebut dilakukan uji validitas, reliabilitas, uji linear berganda Uji f dan Uji t. Berdasarkan hasil pengujian maka dapat disimpulkan bahwa budaya organisasi, kompensasi dan gaya kepemimpinan secara bersama-sama (simultan) maupun secara masing-masing (parsial) memiliki pengaruh yang signifikan terhadap kinerja karyawan. Variabel kompensasi pada Pr. Sumber Barokah di Sidoarjo berdasarkan hasil penelitian pada analisis linear berganda terbukti menjadi variabel yang dominan.
\end{abstract}

Kata kunci : Budaya Organisasi, Kompensasi, Gaya Kepemimpinan, dan Kinerja

\begin{abstract}
Tobacco is one of the most important commodities in Indonesia. The main products of the widely traded tobacco are cigarettes. The goal to be achieved in this research is to test and analyse about the influence of organizational culture, compensation and leadership style to the employee's performance in the Pr. Sources of Barokah in Sidoarjo. This research conducted data retrieval is done by meeting the owner of Pr. Barokah source, after that equate the concept of research that will be researched at the site. And finally to get the poll data researchers spread the statements that have been provided in the questionnaire, the Kuisoner was distributed in 89 respondents randomly. This data retrieval technique uses random sampling of the data conducted validity test, reliability, multiple linear test $\mathrm{F}$ and test T.Based on the test results it can be concluded that the organizational culture, compensation and leadership style together (simultaneous) as well as each (partial) have a significant influence on the employee's performance. Variable compensation on Pr. Barokah sources in Sidoarjo based on the research results in multiple linear analysis proved to be a dominant variable.
\end{abstract}

Keywords: Organizational Culture, Compensation, Leadership Style, and Performance

*Corresponding Author:

Hal: 1-9

Email: nidnod24@gmail.com 
Indonesia adalah negara yang besar dengan potensi dan peluang ekonomi yang menjanjikan. Indonesia memiliki potensi sumber daya - sumber daya yang bisa menjadi peluang memajukan perekonomian. Salah satunya adalah potensi tembakau di Indonesia yang diakui didunia sebagai tembakau terbaik. Tembakau adalah salah satu komoditas paling penting di Indonesia.Produk utama dari tembakau yang banyak diperdagangkan adalah rokok. Pada dasarnya, MEA merupakan wadah yang sangat penting bagi kemajuan negara-negara ASEAN dalam mewujudkan kesejahteraan sehingga keberadaannya harus disikapi dengan positif.

Pada PR. Sumber Barokah merupakan perusahaan milik swasta yang bergerak dalam bidang manufaktur. Latar belakang berdirinya perusahaan ini adalah mendapat inspirasi dari tempat ia bekerja di salah satu perusahaan rokok di tanggulangin Setelahnya ia mengumpulkan uangnya dan memulai usahanya secara kecil-kecilan dan di pasarkan oleh saudara dan keluarganya sendiri, lambat tahun berlalu usaha yang di kelola semakin besar dan minat pasar sangat lah besar dengan bermodalkan tabungan bapak Slamet Budiyono selaku pimpinan pabrik membuat pabrik sendiri yang lebih besar. Untuk mengarahkan karyawan Pr. Sumber Barokah agar sesuai dengan keinginan perusahaan, maka diperlukan Budaya Organisasi agar perilaku karyawan sesuai dengan keinginan perusahaan hal tersebut juga yang menjadi pegangan karyawan saat karyawan tersebut bertindak atau berperilaku. Kompensasi yang diberikan kepada karyawan Pr. Sumber Barokah yang diberikan kepada karyawan tetapnya adalah Upah minimum Regional, tetapi untuk bidang-bidang yang lain adalah Gaji saat targetnya terpenuhi. Gaya kepemimpinan di Pr. Sumber Barokah menjadi hal yang unik karena tiap-tiap masing kepala bagian memiliki cara memimpin yang khas dalam mengarahkan karyawan di Pr. Sumber Barokah.

\section{TINJAUAN PUSTAKA}

\section{Budaya Organisasi}

Menurut Susanto dalam Nawawi (2017: 5) adalah nilai-nilai yang menjadi pegangan sumber daya manusia dalam menjalankan kewajiban dan perilakunya di dalam organisasi. Nilai-nilai tersebut yang akan memberi jawaban apakah suatu tindakan benar atau salah, dan apakah suatu perilaku dianjurkan atau tidak, sehingga berfungsi sebagai landasan untuk berperilaku.

\section{Kompensasi}

Menurut Hasibuan (2016:118) kompensasi adalah semua pendapatan yang berbentuk uang, barang langsung atau tidak langsung yang diterima pegawai sebagai imbalan atas jasa yang diberikan kepada organisasi.

\section{Gaya Kepemimpinan}

Gaya Kepemimpinan menurut Wahyudi (2017: 122) sebagai cara perilaku yang khas dari seorang pemimpin terhadap para anggota kelompoknya. Dengan demikian, gaya kepemimpinan adalah cara pemimpin berperilaku secara konsisten terhadap bawahan/karyawan sebagai anggota kelompoknya. 


\section{Kinerja}

Mathis dan Jackson dalam Donni (2017: 48) bahwa kinerja pada dasarnya adalah hal-hal yang dilakukan atau tidak dilakukan oleh pegawai/karyawan dalam mengemban pekerjaannya.

\section{METODE PENELITIAN}

\section{Populasi}

Populasi pada Pr. Sumber Barokah sejumlah 115 orang hal tersebut sudah mencakup dari keseluruhan bidang-bidang dalam perusahaan tersebut.

\section{Sampel}

Sampel yang diambil menggunakan Teknik slovin dengan tingkat kesalahan 5/\% atau 0.5 ditemukan sebesar 89 responden

\section{Kerangka Konseptual}

Berdasarkan penelitian ini dapat disajikan bagian yangyang menunjukkan alur penelitian, memudahkan pemahaman hipotesis serta pengaruh variable yang di teliti.

\section{Hipotesis Penelitian}

Menurut Sugiyono (2016:99) Hipotesis merupakan jawaban sementara terhadap rumusan masalah penelitian, di mana rumusan masalah penelitian telah dinyatakan dalam bentuk kalimat pertanyaan. Dikatakan sementara karna jawaban masih belum dapat di pertanggung jawabkan,

Adapun hipotesis sebagai berikut ini:

a. Bahwa variabel Budaya Organisasi, Kompensasi, Gaya Kepemimpinan berpengaruh secara simultan terhadap kinerja karyawan pada PR. Sumber Barokah

b. Bahwa variabel Budaya Organisasi, Kompensasi, Gaya Kepemimpinan berpengaruh secara parsial terhadap kinerja karyawan pada PR. Sumber Barokah

c. Bahwa variabel kompensasi berpengaruh dominan terhadap kinerja karyawan PR. Sumber Barokah.

\section{Lokasi dan Waktu Penelitian}

a. Lokasi dari obyek penelitian ini adalah Pr. Sumber Barokah di Sidoarjo yang beralamatkan di Ketegan, Tanggulangin, Kabupaten Sidoarjo, Jawa Timur 61272.

b. Waktu penelitian ini dilaksanakan pada tanggal 21 Januari 2019 sampai dengan 29 April 2019 untuk melakukan survei lapangan pengumpulan data yang dibutuhkan oleh peneliti.

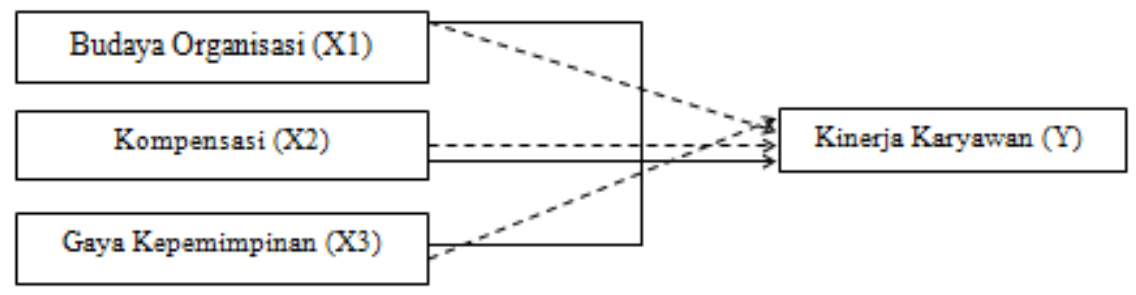

Sumber: Peneliti, 2019

\section{Gambar 1. Kerangka Konseptual}




\section{Jenis dan Sumber Data}

Jenis dan sumber data digunakan dalam penelitian adalah data primer dan data sekunder meliputi data yang sumbernya diperoleh langsung dari perusahaan, Data sekunder dalam penelitian ini data sekunder meliputi dokumen perusahaan mengenai sejarah perusahaan, struktur organisasi, deskrpisi karyawan dan jumlah karyawan Pr. Sumber Barokah di Sidoarjo.

\section{HASIL ANALISIS DAN PEMBAHASAN}

\section{Uji Validitas}

Bedasarkan tabel diatas nilai $r$ hitung lebih besar dari rtabel. Hal ini berarti masingmasing indikator dari rthitung tersebut valid.

Tabel 1

Hasil Uji Validitas Variabel Budaya Organisasi (X1) di Pr. Sumber Barokah

\begin{tabular}{ccccc}
\hline No. & Item Pertanyaan & (R hitung) & r tabel & Keterangan \\
\hline 1. & $\mathrm{X} 1.1$ & 0.713 & 0,208 & Valid \\
2. & $\mathrm{X} 1.2$ & 0.696 & 0,208 & Valid \\
3. & $\mathrm{X} 1.3$ & 0.758 & 0,208 & Valid \\
4. & $\mathrm{X} 1.4$ & 0.553 & 0,208 & Valid \\
5. & $\mathrm{X} 1.5$ & 0.496 & 0,208 & Valid \\
6. & $\mathrm{X} 1.6$ & 0.698 & 0,208 & Valid \\
7. & $\mathrm{X} 1.7$ & 0.635 & 0,208 & Valid \\
\hline
\end{tabular}

Sumber : Peneliti (2019)

\section{Tabel 2}

Hasil Uji Validitas Variabel Kompensasi (X2) di Pr Sumber Barokah

\begin{tabular}{ccccc}
\hline No & Item Pertanyaan & (R hitung) & r tabel & Keterangan \\
\hline 1. & X2.1 & 0.516 & 0,208 & Valid \\
2. & X2.2 & 0.603 & 0,208 & Valid \\
3. & X2.3 & 0.581 & 0,208 & Valid \\
4. & X2.4 & 0.452 & 0,208 & Valid \\
\hline
\end{tabular}

Sumber : Peneliti (2019)

Tabel 3

Hasil Uji Validitas Variabel Gaya Kepemimpinan (X3) di Pr. Sumber Barokah

\begin{tabular}{lllll}
\hline No. & Item Pertanyaan & $($ R hitung $)$ & r tabel & Keterangan \\
\hline 1. & X3.1 & 0.562 & 0,208 & Valid \\
2. & X3.2 & 0.569 & 0,208 & Valid \\
3. & X3.3 & 0.682 & 0,208 & Valid \\
4. & X3.4 & 0.568 & 0,208 & Valid \\
5. & X3.5 & 0.566 & 0,208 & Valid \\
\hline
\end{tabular}

Sumber : Peneliti (2019) 


\section{Tabel 4}

Hasil Uji Validitas Variabel Kinerja Karyawan(Y) di Pr Sumber Barokah.

\begin{tabular}{lllll}
\hline No. & Item Pertanyaan & (R hitung) & r tabel & Keterangan \\
\hline 1. & Y1 & 0.575 & 0,208 & Valid \\
2. & Y2 & 0.599 & 0,208 & Valid \\
3. & Y3 & 0.696 & 0,208 & Valid \\
4. & Y4 & 0.564 & 0,208 & Valid \\
5. & Y5 & 0.563 & 0,208 & Valid \\
\hline
\end{tabular}

Sumber : Peneliti (2019)

Tabel 5

Hasil Uji Reliabilitas di Pr. Sumber Barokah

\begin{tabular}{llll}
\hline Variabel Penelitian & alpha Cronbrach & r tabel & Keterangan \\
\hline Budaya Organisasi (X1) & 0.872 & 0,6 & Reliable \\
Kompensasi(X2) & 0.740 & 0,6 & Reliable \\
Gaya Kepemimpinan(X3) & 0.802 & 0,6 & Reliable \\
Kinerja Karyawan (Y) & 0.810 & 0,6 & Reliable \\
\hline
\end{tabular}

Sumber : Peneliti (2019)

Tabel 6

Analisis Linear Berganda Coefficients ${ }^{a}$

\begin{tabular}{|ll|c|c|c|c|c|}
\hline \multirow{2}{*}{\multicolumn{2}{|c|}{}} & \multicolumn{2}{|c|}{$\begin{array}{c}\text { Unstandardized } \\
\text { Coefficients }\end{array}$} & $\begin{array}{c}\text { Standardized } \\
\text { Coefficients }\end{array}$ & & \\
\cline { 2 - 5 } & $\mathrm{B}$ & Std. Error & Beta & $\mathrm{T}$ & Sig. \\
\hline 1 & (Constant) & .530 & .260 & & 2.040 & .044 \\
& Budaya organisasi & .234 & .087 & .244 & 2.694 & .009 \\
& Kompensasi & .431 & .082 & .471 & 5.256 & .000 \\
& Gaya Kepemimpinan & .207 & .083 & .214 & 2.479 & .015 \\
\hline
\end{tabular}

a. Dependent Variable: Kinerja

Sumber : Peneliti (2019)

\section{Uji Reabilitas}

Budaya Organisasi (X1), Kompensasi(X2), Gaya Kepemimpinan(X3) dinyatakan reliabel karena alpha Cronbrach yang dihasilkan masing-masing variabel berada di atas $\mathrm{r}$ table (Tabel 5).

\section{Analisis Linear Berganda}

$\mathrm{Y}=0.530+0,234 \mathrm{X}_{1}+0,431 \mathrm{X}_{2}+0,207 \mathrm{X}_{3}$

Adapun penjelasan dari persamaan linier regresi berganda adalah sebagai berikut: Pr. Sumber Barokah di Sidoarjo memiliki pengaruh yang positif, yang berarti variabel bebas yang digunakan dalam penelitian ini mempunyai hubungan yang searah dengan variabel terikat.

$Y=0.530+0,234 X_{1}+0,431 X_{2}+0,207 X_{3}$ 


\section{Analisis Koefisien Determinasi}

Pada tabel 7, diperoleh nilai Adjusted R Square $=0,665=66.5 \%$.

\section{Pengujian Hipotesis}

\section{Uji F}

Berdasarkan hasil penelitian di atas dapat dikatakan bahwa variabel budaya organisasi, kompensasi dan gaya Kepemimpinan secara simultan mempengaruhi variabel Kinerja Karyawan dengan nilai $\mathrm{F}$ hitung positif 59.263 lebih besar dari nilai $\mathrm{F}$ tabel sebesar 2,712 dengan tingkat signifikansi $0,000<0,05$ (Tabel 8).

\section{Uji T}

Berdasarkan hasil penelitian menggunkan Uji t, menunjukkan bahwa :

1. Berdasarkan tabel 9 dapat diketahui bahwa Nilai t hitung pada variabel Budaya Organisasi (X1) sebesar 2.694 dimana nilai t tabel dari penelitian ini adalah 1.988 dengan nilai signifikan variabel Budaya Organisasi (X1) kurang dari 5\%(0,05) yaitu sebesar 0,009.

2. Berdasarkan tabel 9 dapat diketahui bahwa Nilai t hitung pada variabel Kompensasi (X2) sebesar 5.256 dimana nilai t tabel dari penelitian ini adalah 1.988 dengan nilai signifikan Varibael Kompensasi (X2) kurang dari 5\%(0,05) yaitu sebesar 0,000.

3. Berdasarkan tabel 9 dapat diketahui bahwa Nilai t hitung pada variabel Gaya Kepemimpinan sebesar 2.479 dimana nilai t tabel dari penelitian ini adalah 1.988 dengan nilai signifikan Gaya Kepemimpinan kurang dari $5 \%(0,05)$ yaitu sebesar 0,015 .

\section{Uji Dominan}

Dari tabel 10 menunjukan variabel budaya organisasi memiliki koefisien beta sebesar 0,244. Variabel kompensasi memiliki koefisien beta sebesar 0,471 dan variabel gaya kepemimpinan memiliki koefisien beta sebesar 0,214.

\section{Tabel 7}

\section{Koefisien Determinasi ( $\left.\mathbf{R}^{2}\right)$ Model Summary}

\begin{tabular}{llrrrr}
\hline Model & $\mathrm{R}$ & \multicolumn{2}{c}{ R Square } & Adjusted R Square & \multicolumn{2}{c}{ Std. Error of the Estimate } \\
\hline 1 & $.823^{\mathrm{a}}$ & .677 & .665 & .30930 \\
\hline
\end{tabular}

a. Predictors: (Constant), Gaya Kepemimpinan, Kompensasi, Budaya organisasi Sumber: Data diolah peneliti (2019)

Tabel 8

Uji F ANOVA ${ }^{\mathrm{b}}$

\begin{tabular}{|c|c|c|c|c|c|c|}
\hline \multicolumn{2}{|c|}{ Model } & \multirow{2}{*}{$\frac{\text { Sum of Squares }}{17.008}$} & \multirow{2}{*}{$\frac{\text { Df }}{3}$} & \multirow{2}{*}{\multicolumn{2}{|c|}{$\begin{array}{rc}\text { Mean Square } & F \\
5.669 & 59.263\end{array}$}} & \multirow{2}{*}{$\begin{array}{l}\text { Sig. } \\
.000^{\mathrm{a}}\end{array}$} \\
\hline 1 & Regression & & & & & \\
\hline & Residual & 8.132 & 85 & .096 & & \\
\hline & Total & 25.140 & 88 & & & \\
\hline
\end{tabular}

a. Predictors: (Constant), Gaya Kepemimpinan, Kompensasi, Budaya organisasi

b. Dependent Variable: Kinerja 
Tabel 9

Hasil uji t di Pr. Sumber Barokah

\begin{tabular}{lllll}
\hline Variabel & $\mathrm{T}_{\text {hitung }}$ & $\mathrm{T}_{\text {tabel }}$ & Sig & keterangan \\
\hline Budaya Organisasi (X1) & 2.694 & 1.988 & 0,009 & Sig $<0,05$ \\
Kompensasi (X2) & 5.256 & 1.988 & 0,000 & Sig $<0,05$ \\
Gaya Kepemimpinan (X3) & 2.479 & 1.988 & 0,015 & Sig $<0,05$ \\
\hline
\end{tabular}

Sumber : Peneliti (2019)

Tabel 10

Hasil Uji Koefisien Dominan/Beta Standardize di Pr. Sumber Barokah

\begin{tabular}{ll}
\hline Variabel & Standart beta \\
\hline Budaya Organisasi (X1) & 0,244 \\
Kompensasi (X2) & 0,471 \\
Gaya Kepemimpinan (X3) & 0,214 \\
\hline
\end{tabular}

Sumber : Peneliti (2019)

\section{SIMPULAN}

Berdasarkan hasil yang sudah dilakukan mengenai variabel budaya organisasi, kompensasi dan gaya kepemimpinan terhadap Kinerja Karyawan Pr Sumber Barokah di Sidoarjo dapat disimpulkan: 1) Terdapat pengaruh secara simultan antara variabel budaya organisasi, kompensasi dan gaya kepemimpinan terhadap Kinerja Karyawan. Dapat disimpulkan bahwa jika Budaya organisasi, Kompensasi dan Gaya kepemimpinan ditingkatkan secara bersama-sama maka Kinerja Karyawan akan meningkat. 2) Terdapat pengaruh dari variabel Budaya organisasi, Kompensasi dan Gaya kepemimpinan terhadap Kinerja Karyawan PR. Sumber Barokah di Sidoarjo secara parsial memiliki pengaruh masing-masing terhadap Kinerja Karyawan. 3) Diantara ketiga variabel yaitu Budaya organisasi, Kompensasi dan Gaya kepemimpinan variabel yang dominan mempengaruhi Kinerja Karyawan adalah variabel Kompensasi dengan besarnya pengaruh secara persentase $47,1 \%$ terhadap kinerja karyawan. Kompensasi menjadi motivasi atau semangat tersendiri untuk karyawan Pr. Sumber Barokah. Berdasarkan hasil penelitian dan kesimpulan yang telah disajikan maka selanjutnya peneliti menyampaikan saran-saran yang kiranya dapat memberikan manfaat pada pihak-pihak yang terkait atas penelitian ini. Adapun saran-saran yang dapat peneliti sampaikan adalah sebagai berikut: Bagi peneliti lain, peneliti lain sebaiknya lebih mengembangkan teori mengenai budaya organisasi, kompensasi dan gaya kepemimpinan terhadap kinerja karyawan yang meneliti mengenai variabel tersebut masih sangatlah minim. Terlebih lagi peneliti harus dapat memilih antara karyawan tetap, kontrak maupun outsourching guna mendapatkan keabsahan data. Bagi Perusahaan, Pemimpin harus mampu meningkatkan rasa budaya organisasi karyawan agar para karyawan mentaati peraturan yang ditetapkan oleh perusahaan, dan bertanggung jawab terhadap tugas-tugas yang diberikan sehingga tidak ada masalah dalam keterlambatan pencapaian target perusahaan. Harus meningkatkan pengawasan dalam kinerja karyawan dan penyelesaian tugas agar para karyawan mampu menghasilkan produk yang berkualitas tinggi dan tepat waktu. 


\section{DAFTAR PUSTAKA}

Briyan Cadalora Putra. (2018). Pengaruh Gaya Kepemimpinan,Budaya Organisasi, dan Komitmen Organisasi terhadap Kinerja Karyawan CV Sinar Sejati di Bojonegoro. Jurnal Manajemen Branchmarck Vol 4, Issue 3.

Busro, (2018). Teori-teori Manajemen Sumber Daya Manusia, Prenadamedia Group, Jakarta.

Edison, Emron, dkk, (2017). Manajemen Sumber Daya Manusia. Penerbit CV. Alfabeta Bandung.

Fadillah, Rozi, (2017). Pengaruh Kompetensi dan Lingkungan kerja Terhadap Kinerja Karyawan pada kantor bank Kalsel cabang pembantu di Banjarmasin, Jurnal. Universitas Lambung Mangkurat, Banjarmasin.

Hasibuan, (2016). Manajemen Sumber Daya Manusia, Edisi 19, Bumi Aksara, Jakarta

Junaedi,( 2010), Tabel Ttabel, Ftabel, Rtabel diakses dari http://junaidichaniago.wordpress.com

Lalamentik, Agnes Adelvin, dkk, (2018). Pengaruh Gaya Kepemimpinan, Komunikasi, dan Kompensasi Terhadap Kinerja karyawan pada Kantor Kekayaan Negara dan Lelang (KPKNL) di Manado. Jurnal EMBA Vol.5 No.1 Maret 2017.

Mas Richan, dkk. (2017). Pengaruh Budaya Organisasi, Karakteristik Individu, Komunikasi Terhadap Kinerja Karyawan di CV. COCARI SIDOARJO. Jurnal Manajemen Branchmark Vol 3 Issue 3, 2017.

Nawawi, Ismail. (2017). Budaya Organisasi Kepemimpinan dan Kinerja. Penerbit Kencana Depok.

Priansa, D.J. (2017). Manajemen Kinerja Kepegawaian. Penerbit CV. Pustaka Setia.

Parashakti, Ryani Dhyan, (2019). Gaya Kepemimpinan dan Motivasi terhadap Kinerja Karyawan pada Bank BJB Cabang Tangerang, Jurnal Universitas Mercu Buana, Jakarta.

Suparyadi, (2015). Manajemen Sumber Daya Manusia. Andi, Yogyakarta.

Sujarweni, V. Wiratna. (2018). Metodologi Penelitian Bisnis dan Ekonomi Pendekatan Kuantitatif. Pustaka Baru Press. Yogyakarta.

Sugiyono. (2018). Metode Penelitian Kuantitatif, Kualitatif, dan R\&D. Cetakan Ke-28, Alfabeta, Bandung.

Sutisna, dkk, (2014). Penerapan Pembelajaran Biologi Berbasis Nilai Imtaq, Hasil Belajar. SCIENTIAE EDUCATIA Volume 3 Nomor 1 Juni 2014

Tirto.id, (2017), Prestasi Rokok Indonesia di ASEAN, diakses dari https://tirto.id/prestasi-rokok-indonesia-di-asean-ckmi. 
Bhencmark

Anodia Tegar Pranatha dkk., Kinerja Karyawan di Perusahaan Rokok

Vol. 1 No. 1

Wahyudi. (2017). Manajemen Konflik Dan Stress dalam Organisasi. Penerbit CV. Alfabeta Bandung.

Wibowo, (2017). Perilaku dalam organisasi, Edisi 5, RajaGrafindo Persada, Depok. 